\title{
We All See the Same Patients: Reflections on the 2012 European School of Internal Medicine
}

Ben J. Wilson MD

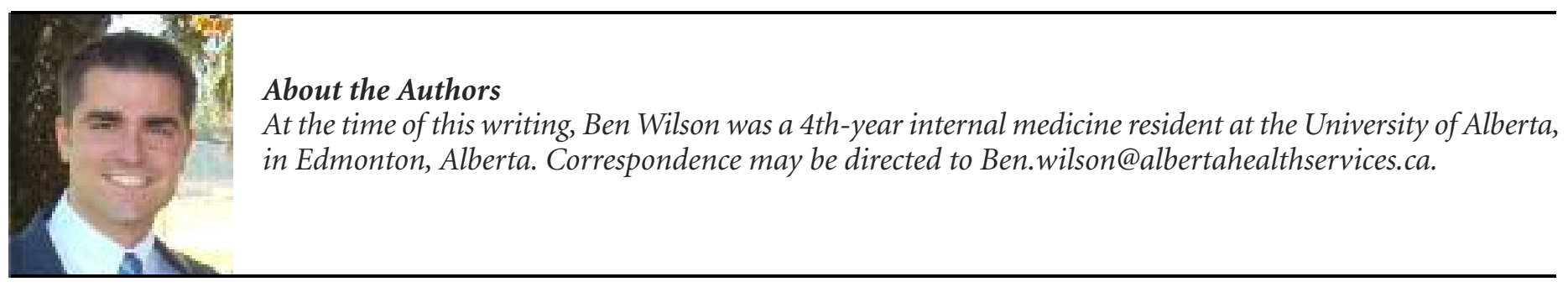

\section{Summary}

The author shares his experiences after attending the 16th annual European School of Internal Medicine (ESIM), in Kusadasi, Turkey.

\section{Résumé}

L'auteur rend compte de sa participation au $16^{\mathrm{e}}$ séminaire estival annuel de l'European School of Internal Medicine (ESIM) qui a eu lieu à Kusadasi en Turquie.

The great Republic of Medicine knows and has known no national boundaries, and post-graduate study in other lands gives that broad mental outlook and that freedom from the trammels of local prejudice which have ever characterised the true physician.

\section{- Sir William Osler, "An Address on the Importance of Postgraduate Study"}

Delegates of the 16th annual European School of Internal Medicine (ESIM), in Kusadasi, Turkey, were greeted with the above quotation. Its strategic placement, just within the front doors of the main conference room, ensured that each of the 41 delegates, from 21 countries, reflected upon its words. Osler's message speaks to the mission of the ESIM. The ESIM was founded in 1998 with an aim to promote excellence in continuing medical education for young internists. In addition to this primary mission, ESIM also seeks to connect young internists by establishing productive social networks.

The ironic inclusion of a Canadian delegate into the "European" school was a source of frequent, amusing conversation. Although I still do not fully understand how I came to be included in this European program, I now appreciate that my participation was in keeping with the collective spirit of the school. This inclusive spirit is perhaps best illustrated by virtue of the non-European status of the host country.

The academic curriculum of this 5-day school was highly innovative. It consisted of lectures on chronic diseases with built-in electronic quizzes; interactive workshops on leadership, medical education, and various European postgraduate training programs; and interactive clinical case studies, with each country being responsible for one presentation.

Listening to the presentations and thoughts of the other attendees was both humbling and inspiring. The more I became aware of the vast knowledge and clinical experience of others, the more I also realized my own limitations. Knowledge gaps that had previously laid unrecognized became conspicuous; I came to appreciate what I did not know.

Amidst the academic and social curricula, I recognized three prominent themes that emerged from this year's school. Firstly, there arose a collective appreciation of the similarity of the patient presentations and diagnoses across countries. As one preceptor aptly summarized, "we all see the same patients." The same spectrum of common and rare diseases challenge internists irrespective of their nationality; internists from across the Western world hear the same hoofbeats, see the same horses, and search for the same zebras. It was this communal experience - the shared triumphs and challenges of the 


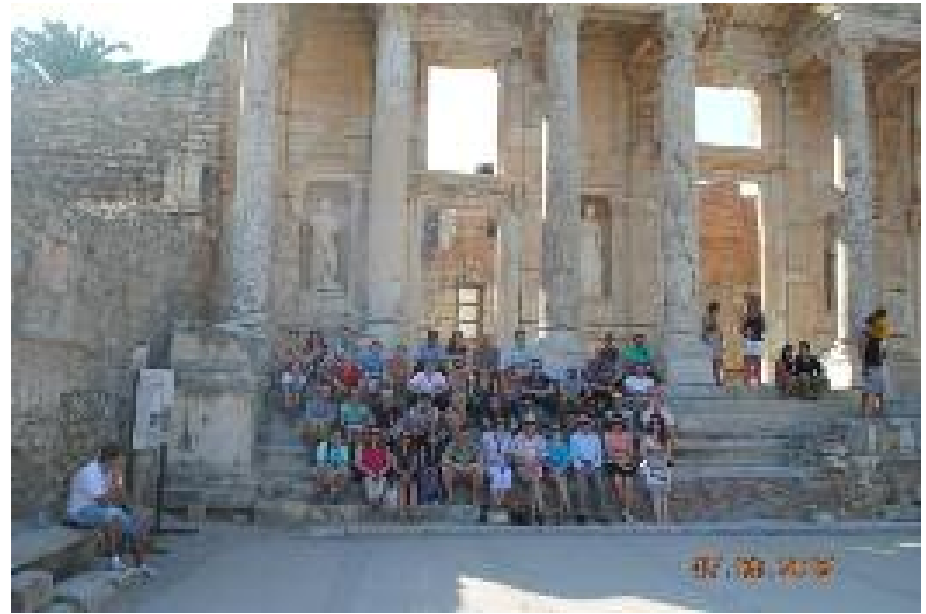

ESIM delegates on the steps of the famous Celsus Library.

international medical community - that Osler referred to as the Republic of Medicine in his quote from over a century ago.

The imprecise and ambiguous definitions of "internists" and the specialty of general internal medicine (GIM) emerged as a second major theme. Many delegates reported that the specialty of GIM did not exist in their respective countries. Those who did report having an official GIM presence complained of a lack of recognition and an ambiguity regarding its scope. Even among these GIM-established countries, there was wide variation in internist roles. Despite these challenges, there emerged an appreciation for the unique value of generalists. In the current climate of increasing specialization, it was felt that generalist and holistic values confer a particular aptitude for leadership, patient care coordination, and costeffective care.

The privileged status of GIM in Canada was the third major theme. This can be illustrated by a brief discussion of the challenges faced by training programs from across Europe. Firstly, it is important to appreciate the marked disparity between the resources and demands of training programs between Eastern and Western Europe, with each region incurring its own particular set of challenges. Delegates from Eastern countries reported that senior residents' wages were equivalent to $\$ 380 \mathrm{CDN}$ per month, they often worked multiple jobs in order to support themselves during residency, and they personally funded their own (sub)specialty training positions. In contrast to these principal financial difficulties, Western countries report strenuous hours (120-hour workweeks and 36-hour on-call shifts), a paucity of consultant positions, and prolonged training requirements with an ever-increasing pressure for producing research output and credentials.
Alternatively, one of the universal criticisms of the Canadian training program in internal medicine was the short (1 month) duration of our rotations. In contrast to European countries that have rotations lasting a minimum of 3 months, Canada was the only participating country to have singlemonth rotations. Many delegates often asked, "What can you possibly learn in only 1 month?" It is certainly conceivable that a single month is insufficient to accrue knowledge and experience that is deep and durable. Rotations of longer duration could enable greater consolidation of knowledge and a more realistic understanding of the day-to-day routine of internists and other specialists; ultimately, this perspective could lead to more informed selection of specialties and careers.

The school also incorporated social activities into the agenda. On two of the afternoons, the academic program was replaced by excursions to local sites of historic significance. On the first of these outings, we found ourselves at the top of Mount Salimus, at the house of the Virgin Mary. This structure, once the purported home of Mary, has been converted into a chapel that is visited by over 100,000 tourists per year. Afterwards, we visited a traditional local village, Sirince. On the second outing, we travelled to the ruins of the ancient city of Ephesus. These well-preserved remains housed the Temple of Artemis, one of the Seven Wonders of the World, and the façade of the famous Celsus Library. It was there, on the steps of this great library, that we received our token certificates of completion. Sitting on those ancient steps with such a unique collection of international internists was a powerful and unforgettable experience. The sublime physical presence of the library's façade, its representation of idealized learning and knowledge, and the conjuring of its ancient history evoked a sense of profound wonder and, once again, humility.

The dramatic closing ceremony was an appropriate conclusion to the school. Participation in such a rich, open, and multinational climate, with exposure to diverse modes of training and thinking, was an invaluable experience. There is remarkable potential that arises from an energetic group of internists from across the world, especially when united by the noble mission of ESIM. I am excited to discover the fruits that will inevitably result from the collaborations inspired through the school.

\section{Acknowledgement}

I wish to thank the Canadian Society of Internal Medicine for the ESIM Travel Award. This financial support was greatly appreciated. 